\title{
The Moral Economy of Austerity: analysing UK welfare reform.
}

\begin{abstract}
This paper notes the contemporary emergence of 'morality' in both sociological argument and political rhetoric, and analyses its significance in relation to ongoing UK welfare reforms. It revisits the idea of 'moral economy' and identifies two strands in its contemporary application; that all economies depend on an internal moral schema, and that some external moral evaluation is desirable. UK welfare reform is analysed as an example of the former, with reference to three distinct orientations advanced in the work of Freeden (1996), Laclau (2014), and Lockwood (1996). In this light, the paper considers challenges to the reform agenda, drawn from $3^{\text {rd }}$ sector and other public sources. It outlines the forms of argument present in these challenges, based respectively on rationality, legality, and morality, which together provide a basis for evaluation of the welfare reforms and for an alternative 'moral economy'.
\end{abstract}

Key words: moral economy, ideology, welfare, rationality, legality, morality Word count: 9,360

In our intellectual division of labour, treatment of the normative aspects of social life has traditionally been the terrain of moral philosophy, both in abstract determinations of right and wrong, and in their potential application to concrete ethical dilemmas. However, in recent years sociologists have begun to make the case for an approach to morality that is less concerned with the generation and application of normative principles, and more with the sources and consequences of varied moral frameworks present in society. Such an approach could rest on an examination of the social dynamics at play in competing conceptions of social worth (e.g. Sayer, 2005; Skeggs, 2012), on an interrogation of socially patterned frameworks of meaning (Hitlin and Vaisey, 2013), on the role of dominant interests and moral entrepreneurs in drawing moral boundaries (Lukes, 2010), or on analysis of the boundary work involved in formulations and justifications of social policy (Atkins, 2010; Steensland, 2006). Given this background, Hitlin and Vaisey (2013:53-4) argue that the sociological import of the study 
of morality lies in the fact that while 'morality can bind groups together... it can also be the subject of negotiation, contestation, and exclusion'.

One aspect of the implied agenda for research must therefore be a consideration of dominant uses of the concept of morality in public life, their implications for (re)shaping the social order, and the form and content of challenges to the meanings and judgements they entail. It is perhaps unsurprising that these reflections and developments in sociological thinking have run parallel to the emergence of a rhetoric of morality in contemporary political parlance. One example is found in the Conservative Party’s (2008:12) Responsibilities Agenda, and the assertion that: 'ending Britain’s welfare culture is a moral duty for any progressive government', reinforced by David Cameron's (2012) later statement that the ensuing welfare reforms were part of a 'moral mission' for the country. The present article considers the underpinning rationale of this claim, the form and content of the challenges it has provoked, and the conceptual tools that can be brought to bear on analysis.

\section{Moral economy revisited}

As a preliminary to this exercise, it may be helpful to revisit the idea of 'moral economy' as adopted by E.P.Thompson (1971) to address the way behaviour in the face of hunger is modified by custom, culture and reason. Analysing crowd reaction to food shortages in $18^{\text {th }}$ Century England, Thompson argued that in almost every case there was a 'legitimising notion' at work, 'informed by the belief that they were defending traditional rights or customs...supported by the wider consensus of the community' (p78). This belief was grounded in norms and obligations supported by a paternalist model of production and distribution, and by the common law, which in combination constituted the moral economy of the poor. Thompson’s analysis was concerned with disturbances that erupted as this paternalist model began to break down, and the same conceptual framework was applied in James Scott's (1976) study of rebellion and subsistence in South East Asia.

The idea of 'moral economy' has since been subject to considerable debate and has been taken up and applied to contemporary circumstances by a number of writers (Sayer, 2007, 2000; Fassin, 2005, 2009; Clarke and Newman, 2012), while Booth (1993; 1994) provides a helpful discussion of what is 
involved in this transposition. Drawing on Polanyi (1957), he sees the core of pre-industrial moral economy to rest on the notion of embeddedness, through the non-market integration of economic activity into broader social relations and their underpinning values. The model of the modern market economy then implies the reverse arrangement, in that society itself becomes embedded in the economy and is fashioned accordingly, even to the extent of re-shaping individual behaviour and motivations. Booth, however, finds these characterisations to be based on a false dichotomy, and he rejects any implication that there is no calculative, maximising behaviour in pre-market societies, while also arguing that the market itself is embedded in both a normative and institutional framework. Rather he depicts the transition to market society as entailing a normative shift from status to contract, and crucially suggests that what is involved in this move is 'a moral redrawing of the community and of the place of the economy within it...a new form of moral embeddedness' (Booth, 1994:661).

Based on these reflections, Booth (1994:662) offers the idea of moral economy as both a prompt and a language for thinking normatively about the economy, to argue that 'all economies...are moral economies, embedded in the (ethical) framework of their communities', and so to focus attention on role of the economy in the 'architecture' of community (p663). This revised sense of 'moral economy' entails a holistic view of society and the moral presuppositions that underpin its interrelations, while 'moral' in this context is not an evaluative descriptor of a given arrangement, but an element of all socio-economic systems. The appearance of explicit references to morality (as in Conservative discourse) is not, therefore, the necessary marker of a moral economy at work. However, the appearance of such references at a given moment is a likely indication that some significant development is afoot, to be supported by the embedding of an associated value frame. Indeed, while the term 'moral economy' was developed to address the breakdown of reciprocal arrangements in pre-industrial economies, and its possible linkage to protest and rebellion, moral economy investigation can just as well extend to the refashioning of public sentiment to support a distinct moral foundation for economic relations.

It is in this sense that all economies are moral economies, or more accurately that the functioning of all economic systems will imply and to some degree depend upon, a particular moral form. Other 
contemporary moral economy writers have arrived at similar conclusions, and they have in common a wish both to recognise the internal moral underpinnings of any economic system, while also holding onto the possibility of evaluating such a system from the outside, by independent criteria of value. We need, however, to distinguish these two different strands in contemporary application of the term moral economy, which are treated separately in the present article, taking first an illustrative example of the claim that all economies are moral economies, and coming later to the question of standards and means of contestation. The first strand raises a question as to the process by which re-embedding happens, and the second strand, the appropriate criteria for judgement.

Re-embedding the economy: process

My illustrative example addresses the moral economy of austerity Britain, and the following description is derived from policy documents and speeches from the Conservative wing of the Coalition government, in pursuit of their proclaimed 'moral duty' to end Britain's welfare culture. The underpinning political argument may be seen as part of a programme to further embed the British economy in a supporting morality, enforced by radical reform of the welfare system, and expressed in two early papers from the Centre for Social Justice ${ }^{1}$ (Social Justice Policy Group (SJPG), 2006; 2007), and in subsequent policy.

Concerns addressed in the first of these documents include growing social security costs, in the face of successive failures to 'get tough on fraudulent claims' (p13); the alleged causes of dependency family breakdown, educational failure, indebtedness and addiction; the emergent tax credit (TC) economy, itself seen as a form of entrenched (worker) dependency; and a need for closer monitoring of the economically inactive (disabled and single mothers). The solution to these problems centres on a drive to make work pay by means of an integrated welfare system (SJPG, 2007; Conservative Party, 2008; Department of Work and Pensions (DWP), 2010; Duncan-Smith, 2012), which combines benefits for the workless with the TC system, improves work incentives, increases child care support, but enforces tighter conditionality for all groups. This policy programme promises the replacement of a culture of dependency with a culture of responsibility, and the construction of a more efficient 
system of delivery and enforcement, through payment by results to private providers operating an intensified and incremental system of conditionality and sanctions (Conservative Party, 2008; DWP, 2010; Finn, 2011). The force of these proposals is captured by the statement that: 'at present over 80 per cent of the system remains rights based, placing no real demand on it recipients' (SJPG, 2007:32)

The Universal Credit (UC) system (not yet fully implemented) will blur the distinction between inwork and out-of-work claimants and integrate six main means-tested benefits ${ }^{2}$, while other reforms to these benefits have been established in the mean time ${ }^{3}$, almost all including losses. Key changes include: freezing elements of Working Tax Credit from 2011, lowering benefit upratings to 1 per cent per year from 2013, with a complete freeze in the next parliament (Guardian, 2014a; Osborne, 2014), introduction of a cap on the amount of benefit per household (exempting Working Tax Credit recipients), a housing benefit (HB) cut for those ‘underoccupying' a social rented property, a cap on Local Housing Allowance, a reduction in disability support, increased conditionality for the disabled in receipt of Employment Support Allowance (ESA), a job-search requirement for single mothers whose youngest child is aged 5 or over, abolition of the discretionary social fund, and replacement of council tax benefit (CTB) by locally based schemes, many requiring a minimum contribution from claimants. Taken together, we see a number of deterrents to reliance on benefits through cuts, freezes, and conditionality in the name of a 'make work pay' policy, a broadening of the target population for conditionality, an associated extension of the category termed 'dependent', and by implication an erosion of public conceptions of desert.

Cameron's first prime-ministerial conference speech (2010a) gave some clues to the nature of this 'reembedding' process, with his intention to 'change the way we think about ourselves and our role in society', and the rhetoric of key speeches conveys the nature of that change. There are some explicit references to an underpinning morality, especially concerning reform of the welfare system, as in Cameron's (2011) response to the urban riots, which warned against 'moral collapse' and the risks attendant on 'moral neutrality' in relation to the 'moral hazard of welfare'. His conference speech of 2012 refers to his 'moral mission' to cut dependency, citing increased conditionality as the means (Cameron, 2012), while his reply to a rebuke from the Archbishop of Westminster made a 'moral 
case' for welfare reform along similar lines (Cameron, 2014). The content of this morality seems best translated in Conservative parlance as 'fairness', and Cameron adds 'unfairness' to Beveridge’s 'five great evils’ (Cameron, 2012).

The notion of fairness appears repeatedly in Conservative Party speeches since the 2010 election, often paired with 'responsibility', and is 'not just about who gets help' but 'who gives that help through their taxes' (Cameron, 2010). A variety of speeches from the Prime Minister, the Chancellor, and the Secretary of State for Work and Pensions repeat the need to ensure that the out of work population is never better placed than 'hard-working families/people', and that the welfare system is fair to 'the taxpayer' (Osborne, 2012), 'the abused taxpayer (Duncan-Smith, 2013), or 'the hardworking taxpayer' (Duncan-Smith, 2014). There are associative links, largely by textual proximity of reference to the aims of deficit and debt reduction, (eg. Cameron, 2010b) and fraud reduction (eg. Duncan-Smith, 2012), which carry a related moral message.

The policy approach is largely behavioural, assuming a culture of dependency and seeking to correct choices 'skewed' by the welfare system, but the objectives are structural, insofar as: 'Britain cannot run a modern flexible economy, if at the same time, so many of the people who service that economy are trapped in dependency on the state.' (Duncan-Smith, 2014). This then is the moral economy of austerity under the Coalition government; it is not simply a re-run of traditional moralising about welfare claimants, but rather a use of welfare to refashion economic and social relations on a grander scale. Undermining support for the vulnerable is thus one means of embedding a particular kind of economy, which also entails a change in the balance of power between workers and employers, and a worsening of terms and conditions at the lower end of the employment spectrum.

The rhetorical foundations of society?

To understand what is happening in this 're-embedding' process we can look to some key figures in political theory, and especially to Michael Freeden (1996; 2003) on the study of ideology. In his argument, diverse ideologies offer competing interpretations of facts, and each ideology imposes a pattern of meaning that is amenable to substantive analysis. Much of the political work involved is to 
render contestable meanings incontestable, and to give 'core' concepts substance through close association with 'adjacent' concepts, and more loosely with ‘peripheral’ concepts. So Freeden’s argument contains an invitation to think in a contextual and indeed sociological way about the role of ideology and political rhetoric in shaping society, through a more embedded reading than is offered by the abstractions of political philosophy. In the speeches cited above, morality is translated into fairness, which then assumes its content by reference to welfare dependency and the hardworking taxpayer, in loose association with fraud and deficit reduction. So here we have some of the tools for Cameron's (2010) quest to ‘change the way we see ourselves', and to 'shape Britain' in the course of a shift from irresponsibility to austerity (Cameron, 2009).

A further theoretical resource for thinking about this process comes from a different tradition, as outlined in the work of Ernesto Laclau (2014) in his exploration of The Rhetorical Foundations of Society. Both Laclau and Freeden share a view that the role of ideology in social and political life is not so much to mask reality as to shape the way we see it, and in so doing to (re)order aspects of the social world. While Freeden looks at how the contestable is decontested through core and adjacent concepts, Laclau writes of the creation of an absent fullness in the very idea of society, 'projecting into something that is essentially divided the illusion of a fullness and self-transparency' (2014:15). In his account, this is achieved through the construction of a chain of equivalential meanings, whose purpose is to give substance to an unachievable promise - as in the moral pursuit of fairness in the name of hardworking tax payers, set against dependency, deficit and fraud. In Laclau’s terms, such a discursive configuration should be understood as an attempt to close off meaning, in effect stabilising an illusory sense of cohesion and incarnating the impossible 'fullness' of society. In practice, however, the logic of equivalence requires constant negotiation, and for Laclau this reaches its limit in the face of a clear contradiction - as might for example occur when claims to fairness are implicated in the creation of destitution.

While these arguments seem rather distant from the constitution and ordering of the social world, there is one further framework that makes the process more sociologically accessible, and that is David Lockwood's (1996) concept of civic stratification. This work is implicitly concerned with the 
construction of 'moral standing' in society and explores the relations between possession or absence of rights and access to 'moral and material resources'. Briefly put, the argument is that a regime of rights can both shape and be shaped by the moral standing of a given group in society such that an erosion of standing can undermine the enjoyment of, or claim to rights (civic deficit or civic exclusion), while the denial of rights further erodes moral standing. The converse would also apply, in that the accrual of moral standing in society, perhaps through the intervention of civic activists, can lead to an expansion of rights, or to enhanced enjoyment of a right (civic expansion or civic gain). In the case of welfare reform, we see an erosion of moral standing for a social category of 'dependence', its expansion to include the working poor, and its use to question the validity of 'inactivity' as a basis for support, all set against the moral ascendancy of the hard-working tax-payer and harnessed in the cause of legitimising cuts to welfare spending and entitlement.

The three figures mentioned above come from very different traditions of social and political thought, selected for the way they each work at distinct levels and offer different tools for understanding how ideology and rhetoric can operate as social forces. Freeden provides a key to understanding the internal mechanics of a political ideology through the claim to bring definitive, substantive meaning to abstract principles; Laclau's focus is rather on how political forces build their constituencies by forging patterns of equivalence and difference, and lines of opposition, which shape the nature and structure of society itself; while Lockwood traces the moral sentiment generated by such political manoeuvres down to the dynamic construction of civic standing. So there is a certain complementarity between the three approaches sketched out here, each highlighting the way that moral and political sentiment can influence the functioning of social relations, but each also containing scope for movement in the form of challenges to the emergent moral and social order.

As Norval (2000) has argued, ideologies are struggles over socially legimated meanings of political concepts, and the scholar's task is to investigate why one decontestation prevails over another at any given time, pointing to the process by which a moral economy is embedded, or indeed undermined. With regard to the latter, Lockwood notes the role of civic activists in enhancing the moral standing of certain groups and pushing for an expansion of their rights, while Freeden recognises that new sources 
of ideological creativity are likely to be found in pressure group activity. Though Freeden sees that this may be fragmented, and produce only a patchwork of alternative thinking, Laclau argues that the particularity of any given claim can become the occasion for a more general confrontation especially if connections can be made between different subject groups. Of course, while demonstrating in their different ways how ideologies work, none of these approaches draws conclusions or indeed offers guidance as to whether they are good or bad, right or wrong. It may therefore be instructive in what remains of this article to consider the nature of challenges to the Conservative moral mission, their form and foundations, and their implications for an alternative conception of a moral economy.

\section{Challenging austerity: judgement}

If ideology, discourse and rhetoric serve to decontest key concepts and close off meaning, how are they to be challenged, and must a challenge necessarily take the form of a counter-rhetoric? Freeden (2003) argues that ideologies are in fact illusory wholes, made up of fragmented facts and competing values, and while Laclau sees ideological closure as both impossible but necessary to politics, Lockwood envisages social struggles over the moral standing of groups that are targeted by specific policy measures. These elements together suggest spaces of (re)contestation which need not be expressed as a fully formed counter-rhetoric, and a strategy for research is then implicit in Luke's (2010) call to focus on both dominant elites and moral entrepreneurs, and their role in shaping and sustaining moral codes. Hence, his interest in the 'manifold ways in which individuals and social groups escape and resist’ (p554) dominant influences.

In fact, the attempt by political ideology to control representation and interpretation does not mean evidence cannot be brought to bear in evaluating rhetorical positions, or indeed in constructing alternative orientations. Freeden, Laclau and Lockwood each hint at how this might happen, whether through recontesting key concepts, challenging equivalential chains, or revalorising vulnerable groups, and each also gestures towards a likely role for third sector/civil society actors in such a process. With this in mind, we can explore the form and content of challenges to the UK austerity 
agenda emerging from these sources, and a close reading of third sector responses, supplemented by academic, press, and official monitoring ${ }^{4}$, reveals three broad categories of critique. Defined by the form and content of their argument, these are based respectively on rationality, legality, and morality, which also contain echoes of the theoretical possibilities outlined above.

\section{Rationality}

While ideology may represent an attempt to control meaning, it can be judged with reference to both its internal coherence and its exclusions, as supported by Freeden's (2003:95) view of ideologies as 'illusory wholes', and Laclau's recognition that chains of equivalence eventually encounter a 'resistance of meaning' (2014:36). A rationality critique therefore challenges the rhetoric of welfare reform as fairness and morality in its own terms - with reference to its targets, objectives, outcomes, and internal logic.

One critique looks to the focus of emphasis in the welfare reforms and their presentation, and there has been recent comment on the classification and calculation of 'welfare' spending itself (Institute for Fiscal Studies (IFS), 2014a; Guardian, 2014b; Economist, 2014). Thus, the Treasury statement of account $^{5}$ to taxpayers was criticised for submerging the 14 per cent of government spending dedicated to working age benefits (the target of reforms), within the 25 per cent designated as total welfare spending (including personal care services and public service pensions not normally classed as welfare, but excluding state pensions). Child Poverty Action Group (CPAG) ${ }^{6}$ placed these numbers in fuller perspective by circulating Public Expenditure Statistical Analysis figures (PESA, 2014, Table 5.2) that show unemployment benefit to account for only 0.7 per cent of total public expenditure on services, with HB at 3.8 per cent, TC’s at 4.3 per cent, and Sickness/Disability at 6.8 per cent. Others have challenged as misleading any pairing of concern about welfare spending with references to fraud (eg. SJPG, 2006; Duncan-Smith, 2012), in that the $£ 2.4$ billion overpaid to benefit claimants ${ }^{7}$ is less than one third of total unclaimed benefits (Centre for Economic and Social Inclusion (CESI), 2014), and pales to insignificance against the (growing) £34 billion of unpaid tax (Guardian, 2014c) ${ }^{8}$. So here is a rationality critique that highlights distortion in the focus of attention and effort in welfare 
reform, and greatly weakens the chain of association between fairness, benefit cuts and deficit reduction.

Fairness is also placed in contestation by the Centre for Welfare Reform (Duffy, 2014), which shows that despite a government commitment to make cuts fairly, 36 per cent fall on people in poverty, who make up 20 per cent of the population and are less able to bear them (cf. De Agostini et al, 2014), with a greater skew against the disabled and social care users. Indeed, it is argued that many cuts are perverse in generating new social costs, and that likely outcomes are increased personal debt and family breakdown - 'pathways to dependency' the government seeks to address (SJPG, 2006). Other bodies (e.g. Social Security Advisory Committee (SSAC), 2014) note a significant number of claimants are affected by multiple cuts, and there are calls for a cumulative impact assessment which would further undermine claims to 'fairness'. Thus, Oxfam (2014) point out that changes to CTB and HB have meant some families are making payments from subsistence benefits already undermined by reduced upratings, and several organisations (Joseph Rowntree Foundation (JRF), 2014a; Church Action on Poverty (CAP)/Oxfam, 2013; Oxfam, 2014) question whether a guaranteed subsistence level any longer exists, putting at issue a long standing principle of the welfare system.

More detailed argument (Oxfam, 2014) looks to fragmentation and contradiction in the perverse effect of specific measures, which may collide with other aspects of policy. For example, several bodies show welfare reform to have a deleterious effect on child poverty figures (IFS, 2011; Social Mobility and Child Poverty Commission (SMCPC), 2014), leaving projections far short of statutory goals for reducing child poverty, to which the government is legally committed. Implementation of the underoccupancy penalty (bedroom tax) has also encountered difficulties, in part because of insufficient smaller alternative properties (JRF, 2014b) ${ }^{9}$. This has created problems for local authorities, sometimes meaning loss of revenue, while the penalty has had a particularly severe impact on disabled tenants ${ }^{10}$. The cap on the overall amount of benefits a household can receive ${ }^{11}$ is also flawed in that one rationale for this policy is fairness to the average earner, while another is to incentivise employment, yet Oxfam (2014) point out that 40 per cent of those affected are on income support and cannot work because of caring responsibilities, while a quarter are in receipt of ESA (an incapacity 
benefit). Indeed, the Work Capability Assessment has itself been discredited (Guardian, 2012), while performance of the Work Programme has fallen far short of expectations for this group. ${ }^{12}$

Work incentives have a central place in the welfare reform agenda, but SSAC (2014) point to the perverse effect of reforms in undermining the aim to 'make work pay' when 59 per cent of reductions fall on households with someone in work. Though IFS (2014b) calculations on the impact of UC find that taken in isolation the new system would significantly reduce relative poverty, they show this is more than offset by the poverty increasing effect of other changes. A JRF (2014c) study reports that half of adults in poverty are living in households with someone in work, and a number of organisations set the 'make work pay' policy against deteriorating labour market conditions (e.g. Oxfam, 2012). While ONS figures for October 2014 showed unemployment at its lowest since 2008 and employment rates close to an all time high at 73\%, the fall in unemployment was partly through increased inactivity rates (Guardian, 2014d), and the TUC have recorded the worst fall in wages since the 1920 's ${ }^{13}$. Commentators also stress the rise in zero-hours contracts, increased temporary working, and reluctant part-time work and self-employment (Oxfam, 2012; Clark, 2014; Guardian, 2014e ), the latter hitting its highest level for 40 years (Guardian, 2014f). The UC system is to some extent designed to accommodate this 'flexible' labour market, but the SMCPC (2014) express concern that children will simply move between low income workless households and low income working households, with little change in their living standards.

Much attention in relation to rationality and perversity has focused on heightened conditionality and sanctions in the delivery of benefits, steadily increasing from the 1980's onwards (Finn, 2011; Wiggan, 2012; Dwyer and Wright, 2014) but with particular intensity under the Coalition. As of October 2012 (DWP, 2013), a minimum sanction withholds benefit for four weeks, and a maximum sanction for three years, also removing clients from the claimant count for the relevant period. A common criticism of the approach is a tension between advising and coercing (Grant, 2014), while payment of providers by results is thought to have perverse effects in creaming off the most employable and 'parking' the hard to help, many of whom have complex mental or social problems (Grant 2014; Finn, 2011; Manchester Citizen’s Advice Bureau (CAB), 2013; Guardian, 2014g). 
SSAC (2006) has previously questioned how far claimants fully understand the functioning of the system, while and a report from Manchester CAB (2013) found one quarter of those sanctioned did not know why, and 40 per cent had not received written confirmation.

The rationale of the sanctions system is undermined by a report (Oakley, 2014) that a prime provider found one in three clients had health issues, mental health problems, or a learning disability, and that after review and appeal only 28.7 per cent of referrals turned into actual sanctions. Some claimants, especially from more vulnerable groups, lacked clear understanding of the requirements being placed on them, and correspondence was overly long and legalistic. Given the aim of behavioural change, it is unsurprising that the report finds poor communication could yield this endeavour ineffective, while some go further to speak of knowingly tormenting the poor (Webster, 2013). There is concern that families could become cut off both from work and from state support (Oakley, 2014; JRF, 2014), while the system is also thought to produce a high degree of recycling of claimants moving on and off benefits (SMCPC, 2014; JRF/NPI, 2013). Though this is something UC aims to accommodate, in so doing it supports insecurity and poor pay, while also bringing an additional group of low paid workers under the stigmatising effect of conditionality and sanctions, eroding their moral standing.

In sum, the 'rationality' critique undermines government rhetoric not by an explicit counter-rhetoric but by questioning the rationale of policy against evidence and experience, to show that underlying assumptions may be poorly grounded, and that measures may be self-defeating or in conflict with other established objectives. So while an ideological position and its supporting rhetoric are about shaping the way we see the world, their associated policies can nevertheless be assessed in terms of coherence and 'rationality'. While these arguments do not constitute a full-blown counter-rhetoric, they do point to another way of seeing, highlighting flaws internal to welfare reform rhetoric and alerting us to the illusory nature of some of the claims being made, recalling Laclau's 'impossible fullness’ and Freeden’s ‘illusory wholes’.

Legality 
A 'legality’ critique adopts a similar form of argument, but goes further than the 'rationality' approach by asking how far policy is consistent with established legal obligations, which means the courts will often play a determining role. This critique places government policy within a framework of institutionalised commitments that may have accumulated over time, though legality is itself an uncertain field, especially in unfolding areas of the law such as universal human rights, one of Freeden’s (1996:59) fields of contestability.

In relation to welfare reform and austerity politics, one element of contestation lies in attempts to give a stronger role to the International Covenant on Economic Social and Cultural Rights (ICESCR), and bring concrete meaning to existing formal obligations. The UK is a signatory to this Covenant but has resisted signing the optional protocol that secures an individual complaints-mechanism. ICESCR includes the right to an adequate standard of living, and a range of associated rights, all of which should be exercised without discrimination (General Comment 20). In particular, Article 2 requires a signatory state to 'take steps... to the maximum of its available resources, with a view to achieving progressively the full realization of the rights recognized...'. There is a strong presumption against retrogression, which must be justified by reference to the totality of rights and full use of available resources (General Comment 3), so the latter itself presents a basis for challenge (see Elson, 2012), but also scope for varying interpretation.

Much contestation has focussed on the non-discrimination requirement under ICESCR, challenging the fairness agenda by showing the burden of cuts falls particularly on women (Elson, 2012) and people with disabilities (Butterworth and Burton, 2013). It has also been argued that reforms have been introduced 'to pursue a moral agenda of individual initiative', with the government in breach of obligations imposed by the international human right to food (Justfair, 2014). Yet as Palmer (2010) notes: 'There remains a deeply embedded conviction that matters of public finance and resource allocation....are the preserve of the elected branches of government and not of the courts.' However, despite government resistance to accepting the justiciability of social and economic rights, there have been several cases that challenge elements of welfare reform by recourse to domestic law, and to 
rights protected by the European Convention of Human Rights (ECHR) (enshrined in the Human Rights Act (HRA)).

Legal judgments offer an underexploited means of access to contestation over the implementation of policy, and in this process courts become a forum for contextual interpretation of the law through the lived experience of its subjects. Two cases are selected here for comment, given their engagement with central elements of the welfare reform, the nature of the issues raised, and the significant role played by third sector organisations. The case SG and Ors v SSWP [2015] UKSC 16, with interventions from CPAG and Shelter, challenges the benefits cap on behalf of two single parents, both with a child under 5 and both having suffered sexual abuse and domestic violence. The case rested on the discriminatory effects of the cap on single parents and victims of domestic violence, with respect to rights under the ECHR/HRA, but much of the deliberation turns on a consideration of 'fairness'. Here the intervention by CPAG (2015) is of particular interest, offering a clear instance of Freeden’s (1996) argument.

The position set out by CPAG on behalf of the appellants argues that 'fairness' has been emptied of content (para 15), given that the comparison between capped benefit income and that of an average earner disregards benefits available to such earners. The cap applies regardless of family size and includes within its scope benefits paid on behalf of children, contravening the idea of a level playing field between working and workless families (para 12). Furthermore, the aim of incentivising employment through income differentials is weakened by the existence of such differentials prior to the imposition of a cap (para 40). The government seeks to place 'fairness' beyond contention, defending the legitimate objectives of the cap as introducing fairness to tax-payers into the welfare system, making financial savings, tackling a culture of dependency, and incentivising employment. However, this position is advanced despite the fact that mothers of children under 5 are not normally expected to seek work. The government argue that possible exemptions were discussed and rejected by Parliament (UKSC 16, paras 40-43) and that exclusion of child related benefits would 'emasculate the scheme' (para 127). Giving considerable weight to the will of parliament (paras 92-96), the Supreme Court (with two judges dissenting) found the discriminatory effects of the cap to be justified. 
However, three of the five judges expressed concern about non-compliance with the United Nations Convention on the Rights of the Child, while one observed that the cap 'breaks the link between benefit and need' (para 180).

A further case warrants mention, as one that did eventually lead to an over-riding of Parliament in relation to the Coalition's Work Programme and implementation of the Employment Skills and Enterprise Scheme, under which claimants could be required to participate in work related schemes, including unpaid work. The case was brought with the support of Public Interest Lawyers, and succeeded in the Court of Appeal on the charge that the 2011 governing regulations were ultra vires, failing to provide details of the relevant schemes or the requirement of participation. The regulations were therefore quashed, though the judge found against a claim of forced labour. The case was appealed by both respondents and appellants in the Supreme Court (Reilly and Wilson v SSWP [2013] UKSC 68), but Parliament meanwhile retrospectively validated the 2011 Regulations, also adding descriptions of the seven schemes in operation. The Supreme Court found that the 2011 Regulations had provided insufficient information about the relevant schemes, that the first respondent was given no written notice, and that the details given to the second respondent were inadequate - though he was sanctioned with loss of benefits for failure to participate.

The issue again turned on a question of 'fairness', and this point is made repeatedly in the judgment, both in relation to the claimants and as a matter of public interest (e.g. paras 64 and 66), though the court again found against a claim of forced labour. However, there was follow-up litigation (Reilly and Hewstone v SSWP [2014] EWHC 2182 (Admin)) on the fact that the 2011 Regulations governing the scheme were validated retrospectively by Parliament while the case was ongoing, pre-empting decisions on 2,512 pending appeals against unlawful sanctions, in favour of the DWP (paras 49 and 102). The High Court found this retrospective validation to be incompatible with the right to a fair trial for the respondents (Article 6, HRA), meaning that any pending appeals against sanctions were likely to succeed (as illustrated by Hewstone). The judge takes issue with descriptions of the claimants in Parliamentary debate, noting: 'It would be unjust to categorise the claimants in Reilly No.1 as those "who have not engaged with attempts made by the state to return them to work" and 
who should therefore "face the appropriate consequences rather than receiving an undeserved windfall”, as Lord Freud put it.' (para 126). The whole saga takes as a central concern conceptions of fair treatment, and the judgment gives prominent place to what we can term the 'moral standing' of the claimants, as in the civic stratification framework.

While these illustrative cases fall short of complete success, both are significant in seeking to give content to the concept of fairness, elaborating an alternative interpretation and rendering its meaning contestable. They also, in different ways, seek to establish the moral standing of the claimants involved against a discourse of dependency and dis-merit, and so to correct the negative dynamic at play in relation to civic stratification.

\section{Morality}

The rationality critique is clearly limited in functioning within the terms of a given policy or set of policies, and thus making no challenge to the wider context in which such policy functions. Legality goes a little further, contesting key issues and principles, but nevertheless operates within a given social and institutional context. However, the rationality and legality arguments outlined above do have an implicit moral content, which becomes more apparent in third sector documentation that takes its force from experience, and recontests morality as the prevention of human suffering. Thus, in a letter to the Daily Mirror ${ }^{14}, 27$ Anglican Bishops and 16 other faith leaders state that the Prime Minister has 'an acute moral imperative to act' on growing numbers going hungry, describing the government's welfare cuts as a 'national crisis' and a 'disgrace'. The letter cites 5,500 people admitted to hospital in the UK for malnutrition, mothers skipping meals to feed their children, and many facing the choice to heat or eat. It also states: 'Britain is the world's seventh largest economy and yet people are going hungry...over half of the people using foodbanks have been put in that situation by cut backs to and failures in the benefit system...' The founder of the End Hunger Fast campaign ${ }^{15}$ similarly comments that: 'For David Cameron to defend what is happening in the welfare system as part of his "moral mission” when the reality is that hundreds of thousands of Britain's have been left hungry is truly shocking'. 
Such an approach overrides arguments based on 'fairness', and comes closer to the notion of a moral absolute based on survival needs (see Shue, 1996; Justfair, 2014). The background to this argument is provided by a number of reports documenting poverty and suffering in the UK; the ESRC funded Poverty and Social Exclusion project (2013) found that even before the effect of cuts were felt 9 per cent of households (2.3 million) could not afford to heat living areas of their home, over half a million children (4 per cent) lived in families that could not afford to feed them properly, and over 3.5 million adults (8 per cent) could not afford to eat properly themselves. Two IFS reports (2014; 2011) respectively found that 14.6 million people (23.2 per cent) were in absolute poverty (measured after housing costs), and that by 2020 absolute child poverty is set to rise by 9.6 per cent ${ }^{16}$ (see also Guardian, 2014h).

While the uprating of benefits was reduced for a second time in April 2014 (with further reduction planned), the cost of a 'minimum basket of goods' (a standard poverty measure) was found by JRF to have risen by between one quarter and one third from 2008 to 2014 (JRF, 2014a), and we have noted the impact of cuts to CTB and HB in requiring payments from subsistence income. Commonly recognised effects (Duffy, 2014; Oxfam, 2012) are reliance on loan sharks, financially punitive use of bailiffs for debt collection, and growing dependence on food banks, with the Trussell Trust reporting over 900,000 users for 2013-14. The Trust found the main causes to be benefit delays (30 per cent), low income (20 per cent) and benefit changes (16 per cent), ${ }^{17}$ and now issues kettle boxes to clients who cannot afford to run their cooker, and provides a cold box that does not require any fuel (Guardian, 2014i). The response to a Church of England (Sentamu (ed), 2015) call for renewed commitment to solidarity and 'the commonality of the human journey' (p29), was an emphasis on job creation and a strong economy ${ }^{18}$. For Sentamu et al, the economy is not enough.

The conclusion drawn by several organisations (JRF, 2014a; Oxfam, 2013; 2014) is that: 'the social safety net is failing in its basic duty to ensure that families have access to sufficient income to feed themselves adequately' (CAP/Oxfam, 2013). In an echo of the moral economy of subsistence societies (Scott, 1976), the implicit judgment is that the means of basic survival is an absolute right that overrides policy concerns, a view also aired in a Parliamentary debate on the use of foodbanks: 
'The final verdict on any government is how they treat the poorest in society during the hardest of times. The rise in need for foodbanks is a horrifying indictment ${ }^{19}$. Although benefit sanctions are one factor fuelling their use, Webster (2013:11) reports that no impact assessment was deemed necessary for the 2012 Job Seekers Alllowance Regulations that tightened sanctions, because 'they impose no cost to the private sector or civil society organisations'. There is an implicit challenge here to the divisions which underpin this kind of auditing, and it has the potential to move beyond a questioning of administrative calculation to engage in what Nussbaum (2007) terms the cultivation of compassion - which she also views as indispensible to legal rationality. Her argument is an attempt to bridge social divides through a morality of common humanity, and the civil society actors who document the suffering that flows from a punitive constriction of welfare are all in some way engaged in this endeavour.

Their accounts of the experience and effects of welfare reform feed into a debate about purpose, and Wiggan (2012) writes of 'the subordination of social policy to the goals of economic policy', such that organisations like Oxfam (2012) signal a need to 'rethink what we value as a society'. This orientation moves us from an analysis of the 'moral economy' internal to the rhetoric of the Coalition government, to an external evaluation of the morality of its aims and effects, or in Booth's (1993) terms, restores the question of telos to economic thinking. Here we find an attempt to claim the language of morality for a different set of objectives, and one step in this direction is to shift the emphasis away from the behavioural assumptions and disciplinary measures that underpin attacks on 'dependency culture'. The alternative is to look instead to securing 'fairness' through guaranteed standards in both employment and subsistence, coming closer to a capabilities approach to rights that looks to human flourishing and dignity (Sen, 2005). This might be construed as a different way of seeing, and at least in part as an exercise in revalorising the poor, offsetting the negative elements of civic stratification bred by a stigmatising conception of dependency. Such an approach would place the realisation of human potential at the heart of public policy by taking fellowship as the motivational basis for social co-operation, and endorsing a list of basic capabilities as the appropriate goal (see Nussbaum 2007). 
Following Will Hutton (2014), such an exercise could begin with recognition that 'public services and safety nets are not inconvenient social burdens' but are a 'collectively owned means of guarding against the hazards and risks that every human might confront'. Others seek to challenge the 'deficit scare' as a justification for shrinking the state at the expense of the most vulnerable, and for cutting benefits while reducing taxation for the better off (Keegan, 2014; De Agostini et al, 2014). There is also a reframing of dependency by looking to subsidies for 'too big to fail' banks (Chakrabortty, 2014), to TCs that subsidise employers paying below subsistence wages, to HB that goes to private landlords, (Chu, 2014), and by bringing corporate welfare into the picture. Thus, Farnsworth (2013) cites the Office of Fair Trading statement that available data do not 'present a clear view of the total amount of subsidy provided by the public sector to private business', which is surprising given intense concern over the measurement of 'welfare' spending of every other kind (IFS, 2014a; Economist, 2014).

In fact, the classification and definition of subjects and objects of policy are one means by which social relations are constituted, as reflected in both the civic stratification model and the construction of chains of equivalence, but existing political rhetoric linking deficit, dependency, and morality does not extend to corporate supports. Sinfield (2013:31) points to a presentational issue in which: 'the art is being able to present yourself as a 'giver to' rather than a 'taker from' the state', and asks who really benefits and to what extent from state expenditure. The costs of the bail out to banks left outstanding support in 2011 at 31 per cent of GDP (Guardian, 2011), over four times the current figure for a year's spending on working age benefits (IFS 2014a). The moral economy question may therefore be framed as thus becomes that of 'whose economy?'; (Massey and Rustin, 2014); an attempt to reverse the arrangement described by Booth (1993) whereby the economy embeds its driving goals and values within society. In similar vein, Massey and Rustin (2014:173) argue: 'Neoliberalism represents the market economy as virtually coterminous with society itself, as determining its entire system of values...(whereas) the economy should be seen as a means to the fulfilment of broader human ends.' (Massey and Rustin, 2014: 173). The comment may be read as an implicit invitation to link the purpose of the economy to conceptions of human flourishing, and here 
the economy is not viewed as a technical matter beyond politics, but rather each government policy is seen as one element in a wider narrative, which is accessible to analysis in these terms. The authors argue that economic policy must therefore be understood as part of a cultural and ideological struggle, whose purpose and values are actively constructed and maintained, and are therefore amenable to challenge. Their position arguably contains both a moral and political dimension, in seeking to embed economic purpose within human purpose.

\section{Conclusion}

This paper set out to explore the conceptual tools available for understanding UK welfare reforms conducted in the name of morality, and began with a review of contemporary treatments of the concept of moral economy. Two strands of argument were identified - one, that all socio-economic systems have an underpinning moral schema internal to their functioning, and the other, that some external moral evaluation of such systems should be possible. In terms of the first strand, the welfare reforms and their underpinning rationale may be seen as an attempt at embedding a supporting set of moral presuppositions. For an understanding of this process I have drawn on arguments about the role of political ideology and rhetoric in decontesting key concepts (Freeden, 1996) and establishing an illusion of coherence and 'fullness' (Laclau, 2014), while both approaches can be supplemented by Lockwood's (1996) view of 'moral standing' and civic stratification. However, such argument raises the question of how to evaluate and/or (re)contest such a system - the second strand of the moral economy approach.

We have considered the role of political rhetoric in constructing 'the way we see ourselves', but have also sought ways to approach such framing in the process of critique. In fact, the work of both Freeden and Laclau would seem to support a multi-level approach, which need not be confined to the construction of a counter-rhetoric. Drawing on the outputs of third sector organisations, supplemented by other public sources, we have seen that policy can be assessed in its own terms, in the form of 'rationality', to contest claims to internal coherence; it can be assessed against an established framework of commitments, in the form of 'legality', to contest the content of core concepts; and it can be assessed against recognition of human dignity and the aim of human flourishing, in the form of 
'morality'. These three approaches are of course inter-related, and though 'morality' is the closest existing argument comes to a counter-rhetoric, it may nevertheless be strongly supported by 'rationality' and 'legality', while in combination they might furnish the substance for an alternative 'moral economy', in which the realisation of human potential takes central place.

\footnotetext{
${ }^{1}$ Founded by Ian Duncan Smith, currently Secretary of State for Work and Pensions.

${ }^{2}$ Job Seekers Allowance, Housing Benefit, Working Tax Credit, Child Tax Credit, Employment Support Allowance (for the disabled), and Income Support (for the economically inactive)

${ }^{3} \mathrm{~A}$ list of benefit changes under the Coalition is provided by JRF/NPI (2013)

${ }^{4}$ Eg. Social Security Advisory Committee, the Social Mobility and Child Poverty Commission.

${ }^{5}$ https://www.gov.uk/government/news/millions-start-receiving-break-down-of-how-their-tax-isspent

${ }^{6}$ See pic.twitter.com/yqaYPd08XV

${ }^{7} £ 0.8$ billion from official error and $£ 1.6$ billion from claimant error

${ }^{8}$ See also http://leftfootforward.org/2015/02/tax-cheats-cost-far-more-than-benefits-cheats-yet-farfewer-are-prosecuted/

${ }^{9}$ http://www.channel4.com/news/bed-tax-forces-people-out-of-homes

${ }^{10}$ See MA and Ors v SSWP [2014] EWCA Civ 13

${ }^{11} £ 500$ for a workless family and £350 for a single adult - further reduction is planned

${ }^{12}$ The programme has placed one in ten new claimants for three months or more, but only $2.9 \%$ of established claimants

https://www.gov.uk/government/uploads/system/uploads/attachment_data/file/355896/Work_Progra mme_Statistical_Release_Sep14_Final.pdf

${ }^{13}$ http://www.tuc.org.uk/economic-issues/labour-market-and-economic-reports/economicanalysis/britain-needs-pay-rise/uk

${ }^{14}$ http://endhungerfast.co.uk/open-letter-bishops/ $20^{\text {th }}$ February, 2014

${ }^{15}$ http://www.mirror.co.uk/news/uk-news/27-bishops-slam-david-camerons-3164033
} 
${ }^{16}$ http://www.poverty.ac.uk/editorial/1-4-children-poverty-2020-\%E2\%80\%93-ifs-forecast

${ }^{17}$ http://www.trusselltrust.org/stats

${ }^{18}$ http://www.telegraph.co.uk/news/politics/david-cameron/11349601/David-Cameron-facing-rowwith-Church-as-he-profoundly-disagrees-with-Archbishops-attack.html

${ }^{19}$ HoC Hansard, $18^{\text {th }}$ December, 2013 col 820

\section{References}

Atkins, J. 2010 'Moral argument and the justification of policy’, British Journal of Politics and International Relations, 12(3):408-24

Booth, W.J. 1993 'A note on the idea of the moral economy', American Political Science Review, 87(4):949-54

Booth, W.J. 1994 'On the idea of the moral economy’, American Political Science Review, 88(3):653-67

Butterworth, J and Burton, J. 2013 ‘Equality, HRs and Public Service spending cuts’, Equal Rights Review, 11:26-45

Cameron, D. 2009 http://www.politics.co.uk/comment-analysis/2009/04/27/tory-spring-conferencespeeches-in-full

Cameron, D. 2010a http://press.conservatives.com/post/98882674910/david-cameron-speech-toconservative-party-conference

Cameron, D. 2010b www.gov.uk/government/.../prime-ministers-speech-on-the-economy,

Cameron, D. 2011 https://www.gov.uk/government/speeches/pms-speech-on-the-fightback-after-the$\underline{\text { riots }}$

Cameron, D. 2012 http://www.telegraph.co.uk/news/politics/conservative/9598534/David-

Camerons-Conservative-Party-Conference-speech-in-full.html

Cameron, D. 2014 http://www.telegraph.co.uk/news/politics/david-cameron/10646421/David-

Cameron-Why-the-Archbishop-of-Westminster-is-wrong-about-welfare.html

CESI 2014 Take-up of Benefits and Poverty, London: CESI 
Chakrabortty, A. 2014 'Cut benefits? Yes, let’s start with our £85bn corporate welfare handout’, Guardian, $7^{\text {th }}$ October

Chu, B. 2014 'Why Osborne's headline-grabbing claims are wrong', Independent on Sunday, $7^{\text {th }}$ October

CAP/Oxfam, 2013 Walking the Breadline, Oxford: Oxfam

Clarke, J. and Newman, J. 2012 'The alchemy of austerity’, Critical Social Policy’, 32(3):299-319

Clark, T. 2014 'Unwilling freelancers give lie to jobless numbers', Guardian, 29 ${ }^{\text {th }}$ October

Conservative Party 2008 Responsibility Agenda, Work for Welfare, Policy Green Paper 3

CESCR 1990 General Comment 3, The nature of states parties obligations

CESCR 2009 General Comment 20, Non-discrimination in social, economic and cultural rights

CPAG 2015 http://www.cpag.org.uk/content/benefit-cap-cpag-intervention

De Agostini, P. et al 2014 Were we really all in it together? CASE Working Paper 10, London:LSE DWP 2010 Universal Credit: Welfare that Works, London:HMSO, Cm 7957

Duffy, S. 2014 Counting the Cuts, Centre for Welfare Reform

Duncan-Smith, I. 2012 https://www.qov.uk/../news/iain-duncan-smith-welfare-reformsrealised

Duncan-Smith, I. 2014 http://blogs.spectator.co.uk/coffeehouse/2014/01/iain-duncansmiths-speech-on-welfare-reform-full-text/

Dwyer, P. And Wright, S. 2014 'UC, ubiquitous conditionality and its implications for social citizenship', Journal of Poverty and Social Justice, 22(10):27-35

Economist 2014 'How much tax goes on welfare?', $8^{\text {th }}$ November:11

Elson, D. 2012 'The reduction of the UK budget deficit: a human rights perspective', International Review of Applied Economics, 26(2):177-90

Farnsworth, K. 2013 ‘Bringing Corporate Welfare in’, Journal of Social Policy, 42(1):1-22

Fassin, D. 2005 ‘Compassion and repression’, American Anthropological Association, Aug, 20(3):362-87

Fassin, D. 2009 'Another politics of life is possible’, Theory, Culture and Society, 26(5):44-60 
Finn, D. 2011 'Welfare to work after the recession’, Social Policy Review, 23:127-46

Freeden, M. 1996 Ideologies and Political Theory, Oxford: OUP

Freeden, M. 2003 Ideology: a very short introduction, Oxford: OUP

Grant, A. 2013 'Welfare reform, increased conditionality and discretion', Journal of Poverty and Social Justice, 21(2):165-76.

Guardian 2011 http://www.theguardian.com/news/datablog/2011/nov/12/bank-bailouts-uk-creditcrunch

Guardian 2012 'GP’s call for Work Capability Assessment to be scraped’, 23 ${ }^{\text {rd }}$ May

Guardian 2014a 'Same old medicine from the Chancellor', 30 ${ }^{\text {th }}$ September

Guardian 2014b ‘George Osborne’s tax letters are not about transparency’, $3^{\text {rd }}$ November

Guardian 2014c http://www.theguardian.com/society/shortcuts/2014/oct/21/-sp-benefit-fraud-infacts-and-figures

Guardian 2014d 'Cameron hails fall in unemployment', $16^{\text {th }}$ October

Guardian 2014e 'Self-employment at highest level for 40 years', $21^{\text {st }}$ August

Guardian $2014 \mathrm{f}$ ' 'UK unemployment rate falls to lowest level since 2008 crisis', $17^{\text {th }}$ September

Guardian 2014g 'Almost everyday one of my clients said they felt suicidal', 5 th November

Guardian 2014h 'DWP policies to cut child poverty cannot achieve target', $9^{\text {th }}$ June

Guardian 2014i 'Foodbank issues parcels for those too poor to heat dinner', $20^{\text {th }}$ January

Hitlin, S. and Vaisey, S (eds.), 2010 Handbook of the Sociology of Morality, Springer: New York

Hitlin, S and Vaisey, S. 2013 'The new sociology of morality', Annual Review of Sociology, 39:51-

68

Hutton, W. 2014 'Cameron's tax credo is incoherent, immoral and economically illiterate', Observer, $2^{\text {nd }}$ November

IFS 2014a http://www.ifs.org.uk/publications/7424

IFS 2014b Living Standards, Poverty and Inequality in the UK, London: IFS

IFS 2011 Child and Working Age Poverty from 2010-2020, York: JRF

JRF 2014a A Minimum Income Standard for the UK, York: JRF 
JRF 2014b Housing Benefit Size Criteria, York: JRF

JRF 2014 UK Without Poverty, York: JRF

JRF 2014 Welfare conditionality and Sanctions in the UK', York:JRF

JRF/NPI 2013 Monitoring Poverty and Social Exclusion, York: JRF

Justfair 2014 Going Hungry? The Human Right to Food, London: Justfair

Keegan, W. 2014 'The Conservative’s real deficit problem is a lack of shame', Independent on

Sunday, $7^{\text {th }}$ October

Laclau, E. 2014 The Rhetorical Foundations of Society, London: Verso

Lockwood, D. 1996 ‘Civic integration and class formation’, British Journal of Sociology 47(3):531-

50

Lukes, S. 2010 ‘The social construction of morality’ Hitlin, S. and Vaisey, S (eds.), 549-60

Manchester CAB 2013 Punishing Poverty, Manchester: CAB

Massey, D. And Rustin, M. 2014 ‘Whose Economy?’, Soundings, 57, Summer:170-91

Ministry of Justice 2014 https://www.justice.gov.uk/downloads/human-rights/ICESCR-sixthperiodic-report.pdf

Norval, A.J. 2007 'Review article: The things we do with words', British Journal of Political Science, 30, 313-46

Nussbaum, M. 2007 Frontiers of Justice, Cambridge, Mass: Belknap Press

Poverty and Social Exclusion Project 2012 The Impoverishment of the UK, ESRC grant RES-06025-0052

Oakley, M. 2014 Independent Review of the Operation of the Jobseekers Allowance Sanctions, London:OGL

Observer 2014, 'Revealed: how coalition has helped rich by hitting poor', $16^{\text {th }}$ November

Osborne, G. 2014 http://press.conservatives.com/post/98719492085/george-osborne-speech$\underline{\text { to-conservative-party-conference }}$ 
Osborne, G. 2012 https://www.gov.uk/government/speeches/autumn-statement-2012-chancellors$\underline{\text { statement }}$

Oxfam 2014 Multiple Cuts for Poorest Families, Oxford: Oxfam

Oxfam 2012 The Perfect Storm, Oxford: Oxfam

Palmer, E. 2010 ‘The child poverty act 2010’, European Human Rights Law Review, 10(2):303-15

Polanyi, K 2001 The Great Transformation, Boston: Beacon Press

PESA 2014 https://www.gov.uk/government/statistics/public-expenditure-statistical-analyses-2014

Sayer, A. 2000 'Moral economy and political economy’, Studies in Political Economy, 61(Spring): 79-103

Sayer, A. 2007 ‘Moral economy as critique’, New Political Economy, 12(2):261-270

Sayer, A. 2005 The Moral Significance of Class, Cambridge:CUP

Scott, J.C. 1976 The Moral Economy of the Peasant, New Haven: Yale University Press

Sen, A. 2005 ‘Human rights and capabilities’ Journal of Human Development, 6(2):151-62

Sentamu, J. (ed.) 2015 On Rock or Sand?, London:SPCK

Sinfield, A. 2013 ‘On bringing corporate welfare in’ Journal of Social Policy, 42(1):31-8

Skeggs, B. 2012 'Struggles for value’, British Journal of Sociology, 63(3):472-90

SJPG 2006 Breakdown Britain, London: SJPG

SJPG 2007 Breakthrough Britain, Vol. 2, London: SJPG

SMCPC 2014 https://www.gov.uk/government/publications/response-to-the-consultation-on-thechild-poverty-strategy

SSAC 2006 Sanctions in the Benefit System, Occasional Paper 1, London:SSAC

SSAC 2014 The Cumulative Impact of Welfare Reform, Occasional Paper No. 12, London:SSAC

Steensland, B. 2006 'Cultural categories and the American welfare state', American Journal of Sociology, 111(5):1273-1326

Webster, D. 2013 ‘Jobseekers Allowance sanctions and disallowances’, Working Brief, Autumn:10-1

Thompson, E.P. 1971 'The Moral Economy of the English Crowd in the $18^{\text {th }}$ C', Past and Present 50(Feb): 76-136 
Wiggan, J. 2012 'Telling stories of 21 ${ }^{\text {st }}$ century welfare’, Critical Social Policy, 32(3):383-405 